\title{
KẾT QUẢ ĐIỀU TRỊ PHẪU THUẬT U LỢI Ở PHỤ NỮ MANG THAI
}

\author{
Nguyễn Thị Phương Trà*, Nguyễn Thị Hồng Minh*
}

\section{TÓM TẮT}

Muc tiêu: Đánh giá kết quả điều trị phẫu thuật u lợi bằng dao thường ở phụ nữ mang thai tại Bệnh viện Răng hàm mặt Trung ưởng Hà Nội. Đối tượng và phương pháp: Nghiên cứu được tiến hành trên 30 phụ nữ mang thai trong thai kỳ II (từ tuân thai thứ 13 đến 24), có u lợi có cuống, tiền sử khỏe mạnh và thai kỳ bình thường. Các đối tượng được khám lâm sàng để đánh giá các chỉ số lợi (GI), chỉ số chảy máu rãnh lợi (SBI), đánh giá tình trạng u lợi: vị trí, độ phì đại ở các thời điểm trước phẫu thuật (PT), sau PT 1 tháng, 2 tháng. Phương pháp điều trị: Lấy cao răng, cắt u lợi bằng dao thường dưới gây tê tại chố, xử trí các nguyên nhân gây viêm, phối hợp thuốc kháng sinh, chống viêm, giảm đau, hướng dẫn vê sinh răng miệng. Sử dưng thống kê y học để phân tích các kêtt quả thu được. Kết quả: U lợi có cuống ở PNMT có kích thước lớn, chủ yếu là phì đại độ 3 với tỷ lệ $73,3 \%$, thường gặp ở vùng răng cửa hàm trên với tỷ lệ 53,3\%. Mức độ viêm lợi (GI) tại vị trí u lợi liên quan đến độ phì đại của u lợi ở mức có ý nghĩa thống kê $(p<0,05)$. Sau khi điều trị u lợi có cuống bằng phương pháp phầu thuật với dao thường: chỉ số GI, SBI tại vị trí phẩu thuật có mức giảm đáng kể sau 1 tháng điều trị, sau 2 tháng tiếp tục giảm thêm (sự khác biệt có ý nghĩa thống kê với $\mathrm{p}<0,001$ ). Sau điều trị, tỷ lệ tái pháa u lợi là $6,7 \%$. Kết luâan: Phương pháp điêu trị phẫu thuật cắt u lợi có cuống bằng dao thường thực sự có hiệu quả trong việc cải thiện tình trạng lợi cho bệnh nhẩn là phụ nữ mang thai.

Tư khóa: U lợi có cuống, phụ nữ mang thai.

\section{SUMMARY \\ RESULT OF SURGICAL EXCISION OF GINGIVAL GRANULOMA IN PREGNANT WOMAN}

Objective: To evaluate the results of surgical treatment of gingival granuloma using surgical knife in pregnant women at National Hospital of OdontoStomatology Hanoi. Subjects and methods: The study was conducted on 30 pregnant women in pregnancy II (from the 13th to 24th week of pregnancy), having gingival pyogenic granuloma, healthy and normal pregnancy. Subjects were clinically examined to evaluate the gingival index (GI), gingival bleeding index (SBI), and assess the status of gingival granuloma, consists of: location, hypertrophy at the time of surgery, after surgery 1 month, 2 months. Treatment methods: Scaling, gingival granuloma excision using surgical knife under local anesthesia, treating the causes of inflammation, combined antibiotics, anti-inflammatory, pain relieved medicine,

*Bênh viên Răng Hàm Mặt trung ương Hà Nội Chịu trách nhệm chính: Nguyễn Thị Phương Trà Email:tradentist@gmail.com

Ngày nhận bài: 6/8/2021

Ngày phản biên khoa học: 29/8/2021

Ngày duyệt bài: 18/9/2021 guided oral hygiene. The results were analyzed by medical statistics software. Results: The gingival granuloma in pregnant women has a large size, mainly grade 3 hypertrophy with the rate of $73.3 \%$. It was observed commonly in the maxillary incisor area with the rate of $53.3 \%$. The degree of gingivitis (GI) at the gingival granuloma site was related statistically to the gingival hypertrophy $(p<0.05)$. GI, SBI at the surgical site had a significant decrease after 1 month post-op, and continuing to decrease after 2 months post-op. The difference was significant statistic with $p<0.001$. The recurrence rate of gingival granuloma was $6.7 \%$. Conclusion: The excision procedure of gingival granuloma using surgical knife is really effective in improving the gingival status of pregnant women

Key words: Pyogenic granuloma, pregnant woman.

\section{I. ĐẶT VẤN ĐỀ}

Viêm lợi là bệnh răng miệng phổ biến ở phụ nữ mang thai. Theo nghiên cứu của Lê Bảo Trâm (2009), tỷ lệ viêm lợi ở PNMTlà 90\%[1]. Mức độ trầm trọng của viêm lợi có tương quan với nồng độ hormone sinh dục trong thai kỳ. Nồng độ hormone giới tính trong mô lợi, nước bọt, huyết thanh và dịch lợi cao có thể làm đáp ứng viêm trở lên mạnh hởn [2]. Ở PNMT, vào tháng thứ 2 hay thứ $\dot{3}$ của thai kỳ, ở vùng lợi viêm có thể xuất hiện u lợi có cuống. U lợi bản chất là u hạt, là một loại tắng sản ở lợi, xảy ra khi có các kích thích viêm tại chố và cở thể có sự thay đổi các yếu tố nội tiết. U lợi thai nghén có tỷ lệ mắc tù̀ $0,2-9,6 \%$, trường hợp đầu tiên được báo cáo bởi Blum vào năm 1912. Màu sắc tổn thương thay đổi từ đỏ tía đến xanh thẫm, phụ thuộc vào tổ chức mạch và mức độ ứ trệ tuần hoàn. $U$ thường không đau nếu khổng bị chấn thương do răng đối diện và ăn nhai. Nếu tổ chức hạt tăng kích thước nhanh, có thể lớn tới mức cản trở hoạt động nhai, phát âm, gây chảy máu nhiều, ảnh hưởng đến sức khỏe và tâm lý của PNMT. Để điều trị phải can thiệp ngoại khoa và loại bỏ các kích thích tại chỗ. Vì vậy chúng tôi tiến hành nghiên cứu này với mục tiêu: Đánh giá kêt quả điều trị u lơi có cuống trên phụ nữ mang thai (thai kỳ thứ II)ở Bệnh viện Răng Hàm Mặt TW HNtừ tháng 8/2017-10/2018.

\section{II. ĐỐI TƯỢNG VÀ PHƯƠNG PHÁP NGHIÊN CỨU}

2.1. Đối tượng nghiên cứu. Gồm 30 đối tượng được lựa chọn theo tiêu chuẩn là PNMT thai kỳ II có u lợi có cuống (từ tuần thứ 13 đến tuần thứ 24 thai kỳ) có tiền sử khỏe mạnh và thai kỳ bình thường. Loại trừ những bệnh nhân 
không đồng ý tham gia nghiên cứu, những đối tượng có nguy cơ thai kỳ cao: bệnh tiểu đường, cao huyết áp thai kỳ, tiền sử sảy thai nhiêu lần, có bệnh toàn thân khác đi kèm, đa thai.

\section{2. Địa điểm và thời gian nghiên cứu:}

- Khoa Nha Chu - Bệnh viện Răng Hàm Mặt trung ương Hà Nội

-Thời gian: Từ tháng 8/2017 đến tháng 8/2018.

2.3. Phương pháp nghiên cứu. Nghiên cứu thử nghiệm lâm sàng không đối chứng, so sánh trước và sau điều trị theo thời gian tại 3 thời điểm: trước điều trị, sau điều trị 1 tháng và sau điều trị 2 tháng.

Bước 1: Những PNMT ở thai kỳ II có u lợi có cuống được khám để đánh giá triệu chứng lâm sàng, tư vấn, giải thích điều trị và chọn lựa làm đối tượng nghiên cứu.

Chỉ định phẫu thuật cắt u lợi có cuống ở PNMT: loại bỏ u lợi có cuống có kích thước vượt quá nhú và bờ lợi, dễ gây chảy máu,có thể đau hoặc loét do sang chấn khớp cắn.

a. Lần hẹn thứ nhất: khám, đánh giá tình trang viêm lợi: sử dụng các chỉ số GI, SBI, đánh giá tình trạng u lợi: vị trí, độ phì đại, chỉ định các xét nghiệm máu cơ bản.

+ Lấy cao răng, mảng bám bằng máy siêu âm

+ PT cắt u lợi bằng dao thường dưới gây tê tại chỗ, xử lý các nguyên nhân tại chỗ gây viêm

+ Kê đơn thuốc, hướng dẫn chăm sóc, vệ sinh răng miệng.

b. Lần hẹn thứ 2 sau phẫu thuật 1 tuân): kiểm tra tình trạng lợi và vị trí PT cắt u lợi.

c. Lần hẹn thứ 3 (sau phẫu thuật 1 tháng): khám và đánh giá GI, SBI, độ phì đại lợi tại vị trí phẫu thuật u lợi.

d. Lần hẹn thứ 4 (sau phẫu thuật 2 tháng) : khám và đánh giá các chỉ số GI, SBI, độ phì đại lợi tại vị trí phẫu thuật u lợi.

Bước 2: Nhập và xử lý số liệu.
Bước 3: Tổng hợp số liệu và viết báo cáo.

2.4. Xử lý số liệu. Tất cả bệnh án nghiên cứu sau khi kiểm tra, các số liệu sẽ̃ được mã hóa và nhập và phân tích theo phần mềm thống kê SPSS 16.0.

\section{5. Đạo đức trong nghiên cứu}

- Nghiển cứu được sự đồng ý của Viện Đào tạo Răng Hàm Mặt, Bệnh viện Răng Hàm Mặt Trung Ương Hà Nội

- Đối tượng quyết định tham gia nghiên cứu hoàn toàn tự nguyện, các nội dung điêuu tra được tiến hành khi được sự đồng ý của đối tượng.

- Kêt quả nghiên cứu chỉ phục vụ cho mục đích nghiên cứu, không sử dụng cho mục đích khác.

- Thông tin cá nhân của bệnh nhân hoàn toàn được đảm bảo bí mật.

- Sẵn sàng tư vấn khi đối tượng yêu cầu.

- Kết quả của quá trình nghiên cứu góp phần làm cải thiện các biện pháp điêu trị bệnh, và đưa ra các khuyến cáo tốt nhất cho phụ nữ ở độ tuổi sinh đẻ có phương pháp CSRM đúng cách, bảo vệ SKRM trong suốt thai kỳ và chuẩn bị SKRM trước khi mang thai.

- Tất cả các đối tượng nghiên cứu đều tự nguyện chấp thuận cho phép sử dụng các hình ảnh và số liệu thuộc về cá nhân trong nghiên cứu này.

\section{KẾT QUẢ NGHIÊN CỨU}

\section{1. Đặc điểm lâm sàng u lợi có cuống ở} phụ nữ mang thai

Bảng 1. Mức độ phi đại của u lợi có cuống trước điều trị

\begin{tabular}{|c|c|c|c|c|}
\hline & Độ 1 & Độ 2 & Độ 3 & Tống \\
\hline Số u lợi có cuống & 0 & 8 & 22 & 30 \\
\hline$\%$ & 0 & 26,7 & 73,3 & 100 \\
\hline
\end{tabular}

U lợi có cuống ở PNMT có kích thước lớn, chủ yếu là phì đại độ 3 với tỷ lệ $73,3 \%$ và không có u lợi nào chỉ phì đại phần nhú lợi (độ 1 ).

Bảng 2. Vị trí của u lợi có cuống

\begin{tabular}{|c|c|c|c|c|c|c|}
\hline \multirow{2}{*}{ Vị trí } & \multicolumn{2}{|c|}{ HT } & \multicolumn{2}{c|}{ HD } & \multicolumn{2}{c|}{ Tống } \\
\cline { 2 - 7 } & $\mathbf{n}$ & $\mathbf{\%}$ & $\mathbf{n}$ & $\mathbf{\%}$ & $\mathbf{N}$ & $\mathbf{\%}$ \\
\hline Răng cửa & 9 & 56,3 & 7 & 50 & 16 & 53,3 \\
\hline Răng hàm nhỏ & 2 & 12,5 & 4 & 28,6 & 8 & 26,7 \\
\hline Răng hàm lớn & 5 & 31,3 & 3 & 21,4 & 6 & 20 \\
\hline Tống & $\mathbf{1 6}$ & $\mathbf{5 3 , 3}$ & $\mathbf{1 4}$ & $\mathbf{4 6 , 7}$ & $\mathbf{3 0}$ & $\mathbf{1 0 0}$ \\
\hline
\end{tabular}

Ở PNMT, vị trí thường gặp u lợi có cuống trong miệng nhất là vùng răng cửa hàm trên $53,3 \%$, vùng răng hàm nhỏ là $26,7 \%$.

Bảng 3. Chỉ số GI tai vị trí u lợi theo mức đô phì đại của u lợ có cuống

\begin{tabular}{|c|c|c|c|c|c|c|c|c|c|}
\hline \multirow{2}{*}{ Đô PĐ u Iớ } & \multicolumn{2}{|c|}{ Nhe } & \multicolumn{2}{|c|}{ TB } & \multicolumn{2}{|c|}{ Năng } & \multicolumn{2}{|c|}{ Tống } & \multirow[b]{2}{*}{$\mathbf{P}$} \\
\hline & $\mathbf{n}$ & $\%$ & $\mathrm{n}$ & $\%$ & $\mathbf{n}$ & $\%$ & $\mathbf{N}$ & $\%$ & \\
\hline Độ 2 & 0 & 0 & 4 & 57,1 & 4 & 17,4 & 8 & 26,7 & \\
\hline Đồ 3 & 0 & 0 & 3 & 42,9 & 19 & 82,6 & 22 & 73,3 & 0037 \\
\hline Tống & $\mathbf{0}$ & $\mathbf{0}$ & 7 & 100 & 23 & 100 & 30 & 100 & 0,03 \\
\hline
\end{tabular}


Bảng 4. Chỉ số SBI tại vị trí u lợi theo mức độ phi đại của u lợi

\begin{tabular}{|c|c|c|c|c|c|c|c|c|c|}
\hline \multirow{3}{*}{ 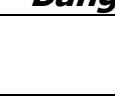 } & \multirow{2}{*}{\multicolumn{2}{|c|}{ Chảy máu TB }} & & & & & & & \\
\hline & & & \multicolumn{2}{|c|}{ Chảy máu nhiều } & \multicolumn{2}{|c|}{ Chảy máu rất nhiều } & \multicolumn{2}{|c|}{ Tổng } & \multirow[b]{2}{*}{$P$} \\
\hline & $\mathbf{n}$ & $\%$ & $\mathbf{n}$ & $\%$ & n & $\%$ & $\mathbf{N}$ & $\%$ & \\
\hline Độ 2 & 0 & 0 & 6 & 31,6 & 2 & 18,2 & 8 & 26,7 & \\
\hline Độ 3 & 0 & 0 & 13 & 68,4 & 9 & 81,8 & 22 & 73,3 & \\
\hline Tống & $\mathbf{0}$ & $\mathbf{0}$ & 19 & 100 & 11 & 100 & 30 & 100 & 0,6 \\
\hline
\end{tabular}

Tại vi trí u lợi: - 82,6\% bệnh nhân viêm lợi mức độ nặngvới u lợi kích thước phì đại độ 3 . Sự khác biệt này có ý nghĩa thống kê với $p<0,05$.

- 68,4\% bệnh nhân có chỉ số chảy máu rãnh lợi nhiều tại vị trí u lợi phì đại độ 3 . Sự khác biệt không có ý nghĩa thống kê có thể do cõ mẫu nhỏ và tất cả chỉ sổ SBI tại vị trí u lợi của 30 bệnh nhân đều rất cao.

3.2. Kết quả điêuu trị u lợi có cuống ở PNMT bằng phương pháp phẫu thuật dao thường.

Bảng 5. Sự thay đối chỉ số GI tại vị trí cắt u lợi sau 1 và 2 tháng điều trị

\begin{tabular}{|c|c|c|c|}
\hline & Trước ĐT & Sau ĐT 1tháng & Sau ĐT 2tháng \\
\hline TB GI & $2,2 \pm 0,32$ & $0,8 \pm 0,46$ & 0,44 \\
\hline Mức giảm & $1,39 \pm 0,40$ & & $0,37 \pm 0,43$ \\
\hline$P$ & 0,00 & & 0,0001 \\
\hline
\end{tabular}

Chỉ số GI tại vị trí phẫu thuât cắt u lợi giảm đáng kể sau 1 tháng điều trị: $1,39 \pm 0,40$ và sau 2 tháng điêu trị giảm thêm: $0,37 \pm 0,43$. Sự thay đổi có ý nghĩa thống kê với $p<0,001$.

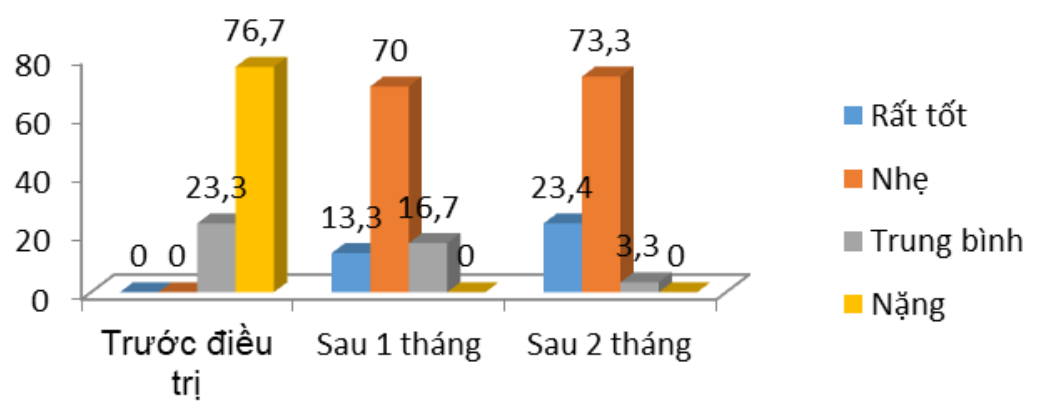

Biểu đồ 1. Hiệu quả cải thiện chỉ số GI tại vị trí cắt u lợi theo thời gian điều trị

Hiệu quả cải thiện tình trạng lợi tai vị trí PT rất rổ rệt. Sau 2 tháng điều trị: 73,3\% chỉ còn viêm lợi nhẹ, 23,4\% hoàn toàn hết viêm.Sự khác biệt có ý nghĩa thống kê với p $<0,001$.

Bảng 6. Sự thay đổi chi số SBI tại vị trí u lợisau 1 tháng và 2 tháng điều trị

\begin{tabular}{|c|c|c|c|}
\hline & Trước $Đ T$ & Sau ĐT 1tháng & Sau ĐT 2tháng \\
\hline TB SBI & $3,01 \pm 0,46$ & $1,05 \pm 0,59$ & $0,6 \pm 0,49$ \\
\hline Mức giảm & $1,96 \pm 0,53$ & & $0,45 \pm 0,49$ \\
\hline$P$ & 0,00 & 0,00 \\
\hline
\end{tabular}

Chỉ số SBI tại vị trí phẫu thuật cắt u lợi giảm đáng kể sau 1 tháng điều trị: $1,96 \pm 0,53$, sau 2 tháng điêu trị giảm thêm: 0,45 $\pm 0,49$. Sự thay đổi có ý nghĩa thống kê với $p<0,001$.

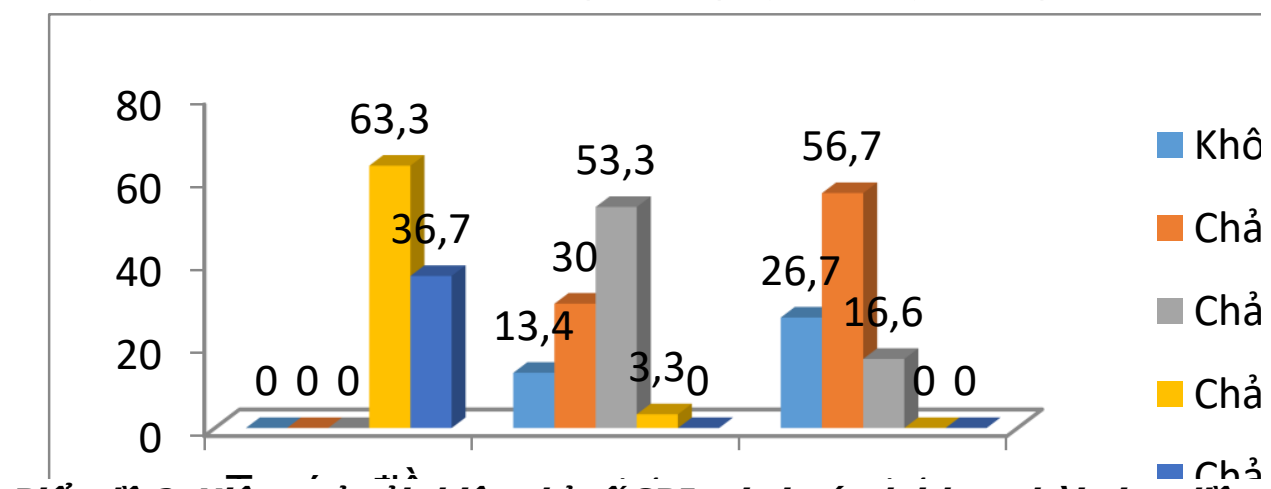

Biểu đồ 2. Hiệu quả càì thiện chỉ sồ SBI tại vị trí u lợitheo thời gian điêutrỉ

Sau 2 tháng điều trị, chỉ số SBI giảm xuống còn $16,6 \%$ chảy máu nhiều và không còn bệnh nhân 
nào chảy máu rất nhiều tai vị trí phẫu thuật.

Bảng 7. Sự thay đổi độ phi đại u lợi có cuống theo thời gian điều trị

\begin{tabular}{|c|c|c|c|c|c|c|c|c|c|c|}
\hline & \multicolumn{2}{|c|}{ Độ 0} & \multicolumn{2}{|c|}{ Độ 1} & \multicolumn{2}{|c|}{ Độ 2} & \multicolumn{2}{|c|}{ Độ 3} & \multicolumn{2}{|c|}{ Tống } \\
\hline & $\mathbf{n}$ & $\%$ & $\mathbf{n}$ & $\%$ & $\mathbf{n}$ & $\%$ & $\mathbf{n}$ & $\%$ & $\mathbf{N}$ & $\%$ \\
\hline Trước ĐT & 0 & 0 & 0 & 0 & 8 & 26,7 & 22 & 73,3 & 30 & 100 \\
\hline Sau ĐT 1 tháng & 28 & 93,3 & 1 & 3,33 & 1 & 3,3 & 0 & 0 & 30 & 100 \\
\hline Sau ĐT 2 tháng & 28 & 93,3 & 0 & 0 & 2 & 6,7 & 0 & 0 & 30 & 100 \\
\hline
\end{tabular}

Sau 1 tháng điều trị có 1 bệnh nhân tái phát ở mức độ phì đại 1 , chiếm 3,33\% và 1 bệnh nhân tái phát với độ phì đại 2 , chiếm 3,33\%.

Sau 2 tháng có 2 bệnh nhân tái phát ở độ phì đại 2 chiếm 6,7\%.

\section{BÀN LUÂ̂N}

- U lợi ở PNMTcó kích thước khá lớn, phì đại độ 3 với tỷ lệ 73,3\%. Bệnh nhân thường không đi khám ngay khi có triệu chứng do tâm lý sợ can thiệp điều trị, thường khi đau nhiều, chảy máu nhiêu là khi kích thước khối u tăng lên thì bệnh nhân mới tới khám. Theo Gordon Nunez (2010) nghiên cứu trên 293 bệnh nhân: u lợi có đặc điểm lâm sàng: kích thước trung bình $1,3 \mathrm{~cm}$, dạng hòn $(71,9 \%)$ với mật độ mềm $(62,3 \%)$ và bề mặt màu đỏ $(73,2 \%)$ [3].

-Vị trí u lợi ở PNMT: thường gặp nhất là vùng răng cửa hàm trên $53,3 \%$,tổn thương đơn lẻ, điều này phù hợp với nghiên cứu của Saravana (2009): $55 \%$ u lợi thai nghén ở hàm trên[4].

-82,6\% bệnh nhân viêm lợi mức độ nặng, 68,4\% bệnh nhân có chỉ số chảy máu rãnh lợi nhiều tai vị trí xuất hiên u lợi.Kết quả nghiên cứu này phù hợp với nghiên cứu của Gordon Nunez (2010), u lợi thai nghén chủ yếu cấu tạo nên từ mô hạt tăng trưởng với nhiều mao mạch nên rất dễ chảy máu [3].

-Chỉ số GI và SBI giảm rõ rệt sau 1 tháng điều trị và giảm thêm sau 2 tháng .Rõ ràng việc phẫu thuật cắt u lợi có hiệu quả tốt trong việc cải thiện tình trạng lợi ở phụ nữ mang thai. Tuy nhiên, tỷ lệ lợi viêm nhẹ sau 2 tháng điều trị vẫn còn $73,3 \%$ và tỷ lệ chảy máu rãnh lợi mức độ ít là $56,7 \%$, không chảy máu là $26,7 \%$. Nguyên nhân do ảnh hưởng của nội tiết tố thai kỳ, có những thay đổi trong mạch máu, các mô liên kết cũng thay đổi trong mô lợi, làm cho các biểu hiện chảy máu lợi không hết hoàn toàn. Theo Hugoson (1970) và Raber-Durlacher (1991) viêm lợi xảy ra lúc mang thai là do tăng nồng độ progesterone trong máu và những ảnh hưởng của nó lên mach máu lợi.

- 6,7\% bểnh nhân bị tái phát nhưng đô phì đại của u lợi giảm. Kết quả này cũng phù hợp với nhiều nghiên cứu trên thế giới như Al Khateeb (2003): 5,8\%; Gordon - Nunez (2010): 8,2\%; theo G.Manegold - Brauer và H.U.Brauer (2014), tỷ lệ tái phát sau phẫu thuật cắt u lợi thai nghén là $3-23 \%$ [5] [3] [6]. Nguyên nhân tái phát ngoài việc không loại bỏ được hoàn toàn tổ chức u lợi đến tận màng xương, bệnh nhân vệ sinh răng miệng chưa tốt còn do nồng độ hormone sinh dục tăng cao trong thai kỳ (theo Amar và Chung 1994) [7].

\section{KẾT LUÂN}

- U lợi ở PNMT có tính chất đơn lẻ, vị trí thường gặp trong miệng nhất là vùng răng cửa hàm trên $(56,3 \%)$, với kích thước khá lớn, chủ yếu là ở mức độ phì đại độ $3(73,3 \%)$. U lợi càng có kích thước lớn thì lợi tại vị trí đó càng viêm nă̆ng và càng dễ chảy máu.

- Tại vị trí phẫu thuật:chỉ số lợi (GI), chỉ số chảy máu rãnh lợi (SBI) có mức giảm đáng kể, lợi chỉ còn viêm nhe hoặc hết viêm, không còn bệnh nhân nào thuộc nhóm chảy máu rãnh lợi nhiều và rất nhiều.

- Sau 1 và 2 tháng điều trị, tại vị trí phẫu thuật u lợi 93,3\% không còn phì đại. Như vậy tỷ lệ tái phát là $6,7 \%$.

\section{TÀl LIỆU THAM KHẢO}

1. Lê Bảo Trâm (2009). Khảo sát tình trang bênh quanh răng, kiên thức, thái độ, thực hành và nhu câu điêu trị ở phụ nữ mang thiai, Luận văn bác sĩ chuyên khoa cấp İ tr. 16-17, tr. 84-85.

2. Mascarenhas $P$, Gapski $R$, Al-shammari $K$, Wang H.L (2003). Influence sex hormones on the periodontium, J.Clin. Peridontol, 30: 671-681.

3. Gordon-Nunez $M A$, de vasconcelos $M$, Benevenuto TG, Lopes MF, et al (2010). Oral pyogenic granuloma: a retrospective analysis of 293 cases in a Brazilian population, J Oral Maxillofac Surg, 68 (9): 2185-8.

4. Saravana GH (2009). Oral pyogenic granuloma: a review of 137 cases, Br J Oral Maxillofac Surg, 47(4): 318-9.

5. Al-Khateeb T, Ababneh K (2003). Oral Pyogenic granuloma in Jordanians: A retrospective analysis of 108 cases, J Oral Maxillofac Surg, 61:1285-8.

6. G. Manegold-Brauer, H. U. Brauer (2014). Oral pregnancy tumour: An update, Journal of Obstetrics and Gynaecology, February, 34: 187-188.

7. Amar S, Chung KM (1994). Influence of hormonal variation on the periodontium in women, Periodontol2000; 6: $79-87$. 